\title{
Antibiyotikli kemik çimentosu hazırlama tekniği
}

\author{
Antibiotic loaded cement preperation
}

\author{
Halil Can Gemalmaz¹, E. Ertuğrul Şener² \\ ${ }^{1}$ Acıbadem Mehmet Ali Aydınlar Üniversitesi Tıp Fakültesi Hastanesi, İstanbul \\ ${ }^{2}$ Gazi Üniversitesi Tıp Fakültesi, Ankara
}

\begin{abstract}
Kemik çimentosu, implantları kemiğe sabitlemek için geliştirilmiş olsa da, çevresine yüksek konsantrasyonda antibiyotik salınımı yapabildiği için, osteomiyelit tedavileri için kullanılabilir. Kemik çimentolarında kullanılabilecek antibiyotiklerin türleri ve miktarları hakkında bazı tartışmalar sürmektedir. İki aşamalı revizyonda, başarılı tedavi için antibiyotik yüklü çimento hâlâ altın standarttır. Revizyon ameliyatları sonrası yüksek enfeksiyon oranı nedeniyle, bazı yazarlar, profilaksi için rutin antibiyotik yüklü çimento önermektedir.
\end{abstract}

Anahtar sözcükler: antibiyotikli çimento, revizyon
Although bone cement was invented for fixing implants to the bone, they can be used for osteomyelitis treatments as they can express high concentrations of antibiotics to the environment. There is still some argument about the expression rate and the kind of antibiotics that can be used in bone cements. In two staged revisions, antibiotic loaded cement is still golden standard for successful treatment. Because of the high post-operative infection rate in revisions, some authors advise routine antibiotic loaded cement for prophylaxis.

Key words: antibiotic loaded cement; revision
K emik enfeksiyonu, diğer adıyla osteomiyelit, kemiğe ait biyolojik nedenlerden ötürü tedavisi çok zor bir durumdur. Ortopedik cerrahide tespit amaçlı kullanılan biyo-materyaller, osteomiyelit gelişme riskini arttırmakta ve tedaviyi zorlaştırmaktadır. Bu durumu açıklayan birçok etmen olmakla beraber, bakterilerin implant üzerinde biyofilm yapması bunların en önemlilerinden biridir. ${ }^{[1-4]}$ Büyük oranda polisakkarit yapıda olan biyofilm, bazı bakteriler tarafından sentezlenen ve özellikle bakterilerin birbirlerine ve biyo-materyal yüzeylere tutunmasını sağlayan bir biyolojik tabakadır. ${ }^{[5,6]}$ Biyofilm, bakterileri bağışlık sisteminden ve antibiyotiklerin diffüzyonundan koruyan bir mikro-bariyer olarak karşımıza çıkar. ${ }^{[7]}$ Kemiğe ait biyolojik nedenler ve implantların üzerini kaplayan biyofilm, implant kullanılan ortopedi ameliyatları sonrası enfeksiyonun tanı ve tedavisini sürekli tartışılan bir konu olarak günümüze kadar getirmiştir.

Kemik çimentosu asıl olarak implantların kemiğe tespiti için kullanılmak üzere geliştirilmiş olsa da osteomiyelit tedavisinde lokal olarak yüksek konsantrasyonda antibiyotik salınımı sağlamak için de kullanılmaktadır. Kemik çimentosu olarak bilinen polimetilmetakrilat (PMMA), toz halindeki polimer ve SIVı halindeki monomerin karıştırımasıyla kıvam alıp, yaklaşık $60-80^{\circ}$ sıcaklığa ulaşan ve egzotermik tepkimeyle sertleşen bir biyomateryaldir. ${ }^{[8]}$ Polimer ve monomerin karıştırılması esnasında içine antibiyotik ilave edilerek yerleştirildiği biyolojik ortamlarda bu antibiyotiklerin yüksek konsantrasyonlarda salındığının fark edilmesinden bugüne $\mathbf{4 0}$ yıla yakın süre geçmiş olmasına rağmen, halen antibiyotikli çimento üzerine tartışmalar devam etmektedir. ${ }^{[9]}$

\section{ANTIBIYYOTIKLI ÇIMENTODAN BEKLENTILER}

Ideal bir antibiyotikli kemik çimentosundan beklenen özellikler; yüksek salınım hızı, uzun salınım süresi ve çimentonun mekanik sağlamlığıdır. ${ }^{[17-21]}$ Tüm bu beklentiler, antibiyotikli çimentonun porozitesine dayanmaktadır. Porozite, antibiyotiksiz çimentonun elle karıştırılması sırasında hacimsel farklar ve kimyasal tepkime nedeniyle oluşan farklı boyutlarda boşluklara verilen isimdir. Yapılan araştırmalar çimentoda por

- Illetişim adresi: Dr. Halil Can Gemalmaz, Acıbadem Mehmet Ali Aydınlar Üniversitesi Tıp Fakültesi Hastanesi, Turgut Özal Bulvarı No: 16 Küçükçekmece, İstanbul Tel: 0212 - 4044661 e-posta: cgemalmaz@gmail.com

- Geliș tarihi: 24 Ocak 2019 Kabul tarihi: 24 Ocak 2019 
çapı ve yoğunluğu arttıkça antibiyotik salınım hızının arttığını; ancak, salınım süresinin ve sağlamlığının azaldığını göstermektedir. ${ }^{[22-24]}$ Çimentoya katılan antibiyotiğin miktarı, fiziksel hali (sıvı-katı), kullanılan çimentonun türü (markası) ve karıştırılma şekli çimentonun porozitesini etkilemektedir. ${ }^{[22,25-31]}$

\section{Antibiyotik, Çimento ve Karıştırılma Şeklinin Salınım Üzerine Etkileri}

Farklı antibiyotiklerin eşit miktarda çimentoya karıştırılması ile antibiyotik salınımının araştırıldığı çalışmalar farklı antibiyotiklerin farklı hızlarda salınım kinetiğine sahip olduğunu göstermektedir. ${ }^{[22,27,32,33-35]}$ Buna örnek olarak tobramisinin gentamisine göre bir miktar, gentamisinin ise vankomisine göre belirgin şekilde daha çok salındığı gösterilmiştir. ${ }^{[33-37]} \mathrm{Bu}$ durumun antibiyotik molekülünün büyüklüğü ve suda çözünürlüğüyle ilgili olduğu düşünülmektedir.[22,27,32-35,38-40] Diğer taraftan, çimentoya katılan antibiyotik miktarının artmasının poroziteyi de arttırdığı ve bunun sonucu olarak antibiyotik salınımının da arttığı gösterilmiştir. ${ }^{[24,33-37,40]}$ Hattâ, birden fazla antibiyotiğin çimentoya karıştırılması sonucu elde edilen karışımın, hem artmış porozite hem de "pasif fırsatçlık" denilen bir metodla antibiyotik salınım hızını arttırdığını gösteren bulgular mevcuttur. ${ }^{[33,34,40]}$ Gentamisin ve vankomisin, bu görüşe uygun olarak çimento içinde birlikte kullanımı önerilen başlıca antibiyotiklerdir. Literatürde birçok çalışma, hem bu iki molekülün kemoterapötik sinerjik etkisini hem de birinin çimento içinde çözünüp salınmasının diğer molekülün salınımı için daha fazla yüzey alanı oluşturmasıyla her ikisinin de salınımlarının arttığını bildirmektedir.[33,34,37,41-44]

Literatürdeki araştırmalar, bazı ticari çimento markalarının diğerlerine göre daha yüksek poroziteye sahip olduğunu göstermektedir. ${ }^{[22,25,26]}$ Çimentonun elle ve hızla çırpılarak karıştırılması, içindeki hacim değişimlerini arttırmak suretiyle daha çok porozite oluşmasına neden olurken, vakum uygulanarak karıştırılması poroziteyi azaltmaktadır. Vakum ile karıştırmak çimentonun mekanik dayanıklılı̆ını arttırsa da antibiyotik salınımını olumsuz etkiler ve bu nedenle antibiyotikli çimento uygulamalarında elle çırparak hızlı karıştırma tercih edilir. ${ }^{[26,44,45]}$

Tedavinin etkinliğini arttırmak amacıyla porozitenin arttırılma çabası, genellikle gereklilikten kaynaklansa $\mathrm{da}$, bunu sağlamak için yapılacak yaklaşımlar antibiyotik salınım süresini kısaltabilir, çimentonun sağlamlığını olumsuz etkileyebilir ve hattâ toksisiteye neden olabilir. Özellikle yüksek dozda antibiyotik kullanımı ile birlikte artan porozite, bir yandan çimentonun fiziksel sağlamlığını olumsuz etkilerken, yüksek serum konsantrasyonlarına neden olarak sistemik toksisiteye neden olabilir. ${ }^{[24,35,46-48]}$

\section{PRATIK UYGULAMADA ANTIBIYOTIKLI KEMIK ÇiMENTOSU}

\section{Hazır Karışım Antibiyotikli Çimento}

Yakın zamana kadar, hazır antibiyotikli spacer'ların ve çimentoların hepsinde antibiyotik olarak tobramisin veya gentamisin bulunmaktayken, son yıllarda gentamisin ve vankomisini birlikte içeren ticari formlar kullanıma sürülmüştür. ${ }^{[4]}$ Bununla beraber, ticari hazır çimento formülasyonlarında, Amerikan Gıda ve İlaç Dairesi (FDA) regülasyonları nedeniyle düşük konsantrasyonda (40 gr. çimento başına $1 \mathrm{gr}$ ve daha az aminoglikozid ve 2 gr vankomisin) antibiyotik bulunmaktadır. Düşük konsantrasyonda antibiyotikli çimentoların protez enfeksiyonu tedavisinde yetersiz kalabileceğini gösteren çalışmalar literatürde mevcuttur. ${ }^{[25,34,43,49]}$ Ayrıca, hazır antibiyotikli çimentoların elle hazırlanan çimentolara göre sağlamlık yönünden \%36'ya varan üstünlük sağladığını gösteren çalışmalar da mevcuttur. ${ }^{[50]}$ Literatürdeki bu bilgiler, hazır antibiyotikli çimentoların primer ve enfekte olmayan revizyon cerrahisinde kullanım için daha uygun seçenek olabileceğini gösterirken, hazır antibiyotikli çimento spacer'larının etkinliğini de kuşkulu hale getirmektedir.

\section{Elle Karıştırılarak Antibiyotikli Çimento Yapımı}

Enfeksiyon etkeninin belirlenip buna göre doğru antibiyotiğin seçimiyle ameliyathane ortamında elle karıştırılarak hazırlanan antibiyotikli çimento uygulamaları, tedavinin başarı şansını arttııı. Diğer taraftan seçilebilecek antibiyotiklerle ilgili kısıtlamalar bulunmaktadır. Bu kısıtlamanın nedeni, kemik çimentosunun monomer ve polimerden oluşan karışımının egzotermik bir reaksiyonla sertleşip donmasıdır. Çimentonun donması sırasında karışımın sıcaklığı $60-80^{\circ}$ 'ye kadar çıkabilir ve bu sıcaklık bazı antibiyotiklerin kimyasal yapısını bozacak seviyededir. ${ }^{[8,32]}$ Buna ek olarak, spacer hazırlamak için kullanılan kalıpların ısı dağılımı üzerine olumsuz etkileri bu sıcaklığın 100-110' 'ye kadar çıkmasına bile neden olabilir. ${ }^{[32]}$ Dolayısıyla, antibiyotikli spacer hazırlarken çimento içine katılacak antibiyotiğin çimento sertleşirken oluşacak sıcaklığa dayanabilmesi, daha sonra da çimentonun fiziksel özelliklerinin eklemde asgari 6-8 hafta fizyolojik yüklere dayanacak kadar güçlü olması ve bu şartları sağlayan çimentodan antibiyotiğin salınımının da in vivo şartlarda kabul edilebilir süreler boyunca yüksek konsantrasyonlarda olması gereklidir. ${ }^{[10,51]}$

Kemik çimentosundan salınım yapan ve hakkında araştırma bulunan birçok antibiyotik mevcuttur. Bunların başında eritromisin, penisilin, sefalosporinler, aminoglikozidler, vankomisin, daptomisin, teikoplanin, florokinolonlar ve klindamisin sayılabilir. ${ }^{[19,29,52,53]}$ 
Kemik çimentolarının, muhtemelen üretim metodlarındaki özelliklerinden dolayı, farklı viskozite ve poroziteye sahip oldukları bilinmektedir. Literatürde birçok farklı çalışma, Palacos ${ }^{\circledR}$ marka çimentodan, Simplex-P, $\mathrm{CMW}$, ve Sulfix çimentolara göre daha fazla miktarda ve daha uzun süre antibiyotik salındığını göstermiştir. Bu durumun, Palacos ${ }^{\circledR}$ çimentonun daha yüksek porozitesine bağlı olduğu düşünülmektedir.[22,25] Ayrıca, çimentonun karıştırılma şeklinin de porozite üzerine etkili olduğu bilinmektedir. Çimentonun elle ve hızla çırpılarak karıştırılması hacim değişimlerini arttırmak suretiyle çimento içinde daha çok porozite oluşmasına neden olurken, vakum uygulanması poroziteyi azaltır. Bu özellik, her ne kadar çimentonun mekanik dayanıkılığını arttırsa da, antibiyotik salınımını olumsuz etkiler ve bu nedenle, antibiyotikli çimento uygulamalarında elle çırparak hızlı karıştırma tercih edilmelidir. ${ }^{[26]}$

Salınım ve mekanik güç parametreleri açısından ideal antibiyotikli çimento karışımı tarifi henüz bilinmemekle beraber, bu tarifin hem gram negatif hem de gram pozitif geniş spektrumu kapsaması gereklidir. Aminoglikozidler bu kapsamda en çok çalışılmış antibiyotikler olup, protez enfeksiyonunda patojen olarak karşımıza çıkan gram negatif ve gram pozitif bakterilere ve anaeroblara karşı doza bağlı etkinlik gösterir. ${ }^{[8]}$ Yapılan araştırmalar aynı miktarda tobramisinin gentamisine göre daha etkili olduğunu göstermekle birlikte; aminoglikozidlerin etkinliğinin doz bağımlı olması, benzer etkinin gentamisin miktarını arttırmakla elde edilebileceğini düşündürmektedir. ${ }^{[24,36]}$ Özellikle ülkemizde sadece ampul formu bulunan gentamisinin antibiyotikli çimento hazırlanması için uygunsuz olabileceği üzerine şüpheler, sıvı antibiyotiklerin antibiyotikli çimento hazırlanmasında kullanılabileceği ve hatta daha yüksek porozite ve buna bağlı salınım sunduğunun gösterilmesiyle birlikte geçerliliğini yitirmiştir. ${ }^{[23,54-56]}$ Ayrıca, dirençli gram pozitif bakterilere karşı en sık tercih edilen antibiyotikler glikopeptidler olup, bu grupta vankomisin en çok araştırılmış moleküldür. Bazı araştırmalar vankomisinin çimentodan kötü salınım kinematiği gösterdiğini ortaya koymuştur. Bu nedenle, karışımda daha yüksek oranlarda bulunması tavsiye edilmektedir. ${ }^{[38,43]}$ Sadece gram pozitif etkinliği bulunması nedeniyle, tek başına kullanımı çok önerilmez. Aminoglikozidlerin glikopeptidlerle birlikte kullanımı sinerjik etki gösterir. Bu nedenle, özellikle dirençli organizma varlığı veya şüphesinde ve direnç gelişiminin engellenmesinin arzu edildiği durumlarda, bunların birlikte kullanımı tercih konusudur. ${ }^{[33,37,41-43]}$

Genel yaklaşım olarak, protez enfeksiyonu ve osteomiyelit tedavisi için kullanılacak antibiyotikli çimentonun $40 \mathrm{~g}$ çimento başına 2 g'dan fazla antibiyotik içermesi önerilir, hatta önerilen antibiyotik miktarının sıklıkla $6 \mathrm{~g}$ ile $8 \mathrm{~g}$ arasında olmasından bahsedilmektedir. ${ }^{[10,39,51]}$ Antibiyotikli spacer hazırlamak için sıvı formda $80 \mathrm{mg}$ gentamisin içeren altı adet $2 \mathrm{~mL}$ 'lik ampulün (toplam $480 \mathrm{mg}$ ) önce $20 \mathrm{~mL}$ sıvı monomere ve ardından toz polimere karıştırıldığı (40 g standart çimento paketi) ve iki aşamalı protez enfeksiyonu tedavisinde kullanıldığı çalışmalar, bu hazırlama metodunu güvenilir ve etkili olarak tanımlamaktadır. Hattâ, yukarıda belirtilen oranda $40 \mathrm{~g}$ çimentoya $480 \mathrm{mg}$ gentamisine ek olarak 3-4 grama kadar vankomisinin de karışıma eklendiği ve elde edilen karışımın istenildiği şekilde hamur kıvamına gelerek donduğu ve bu ikili karışımla yapılan spacer'ların başarılı tedavi sağladığı, çalışmalarla bildirilmiştir. ${ }^{[23,55,56]}$ Ancak burada, sIVI gentamisinin sıvı monomerle, toz vankomisinin de toz polimerle karıştırıldıktan sonra birlikte karıştırılmasının, istenilen kıvamda çimento elde etmek için gerekli olduğu özellikle belirtilmiştir.

\section{Primer Olgularda Antibiyotikli Çimento Kullanımı ve Antibiyotik Direnci}

Aşamalı cerrahi yaklaşım ve modern antibiyotiklere rağmen protez enfeksiyonu tedavisinin zorluğu ve hastanın yaşamı üzerine olumsuz etkileri, günümüzde de önemli bir problem olarak devam etmektedir. Bu durum, primer artroplasti olgularında enfeksiyon gelişme riskini azaltmaya yönelik arayış ve yaklaşımları gerekli kılmıştır. Bunun sonucunda, primer artroplasti olgularında antibiyotikli çimentonun rutin kullanımı gündeme gelmiştir. ${ }^{[1-4,15,16]}$ Ancak, primer olgularda profilaktik antibiyotikli çimento kullanımıyla ilgili de süregelen pek çok tartışmalı konu bulunmaktadır. Bu hususta en önemli konu ise antibiyotikli çimento kullanılarak yapılan primer artroplasti olgularında protez enfeksiyonu gelişmesi durumunda, bunun antibiyotik direncine neden olduğuna yönelik endişelerdir. ${ }^{[16,57]}$ Direnç problemi, ortopedik enfeksiyonlarda en önemli sorunlardan biri olarak karışımıza çıkmaktadır. ${ }^{[57,58]}$

Primer olgularda, profilaksi amaçlı sıklıkla tercih edilen ve ticari olarak ulaşılabilen, FDA'nın da onayladığı tek antibiyotikli hazır çimento karışımı düşük doz aminoglikozid ve polimetilmetakrilat (PMMA) karışımıdır. ${ }^{[1-4,15,16,26,39]}$ Düşük dozdan kasıt, genelde $40 \mathrm{~g}$ çimento için 2 g'dan daha az antibiyotik ise de, hazır antibiyotikli çimento karışımlarında sadece $1 \mathrm{~g}$ aminoglikozid bulunmaktadır. Bununla beraber, değişik antibiyotiklerin elle çimentoya katılmasıyla ve primer protez olgularında kullanımıyla ilgili çalışma ve araştırmalar mevcuttur. ${ }^{[1-4,15]} \mathrm{Bu}$ konuda standardizasyon olmayışı; antibiyotik salınım miktarı ve süresinde, ayrıca çimentonun fiziksel özelliklerinde zafiyetle karşılaşılmasına neden olabilmektedir. Çimentonun 
mekanik olarak yeterince güçlü olmaması ise, özellikle primer artroplastide implant yetmezliğine yol açabilme ihtimali nedeniyle tartışma konusudur. Buna rağmen, primer artroplastilerde antibiyotikli çimentonun enfeksiyon açısından riskli hastalarda akılcı olarak kullanımı kendisine daha çok destek bulabilir. Özellikle diyabetik, immünsuprese, romatoid artritli, sigara içen, dolaşım yetersizliği bulunan hastaların primer artroplastileri esnasında antibiyotikli PMMA kullanımını öneren yazarlar bulunmaktadır. ${ }^{[1,2,16]}$ Diğer taraftan, ameliyathane ortamında primer protezlerin tespitini sağlamak amacıyla arzu edilen antibiyotiklerin çimentoya karıştırılarak kullanılmasının, özellikle çimentonun fiziksel sağlamlığı ile ilgili mekanik problemler yaratabileceğini unutmamak gerekir. ${ }^{[24,35]}$

\section{TOKSISITE}

Parenteral antibiyotik tedavisinin ortopedik enfeksiyonların tedavisinde yetersiz kalabilmesinin temel nedeni, cerrahi alanda ihtiyaç duyulan antibiyotik konsantrasyonunu sağlamak için uygulanması gereken parenteral antibiyotik dozlarının sistemik toksisiteye neden olabilmesidir. Klasik bilgi olarak: antibiyotikli kemik çimentosuyla yapılan lokal tedavilerin, sistemik toksisiteye neden olmaksızın, cerrahi alanda bakteriyel eradikasyonu sağlayacak yüksek antibiyotik konsantrasyonları sağladıkları kabul edilir. Antibiyotikli çimento uygulamalarının toksisite yönünden güvenli olduğunu gösteren birçok çalışma bulunmasına karşın, bunun aksini gösteren çalışmalar da mevcuttur. ${ }^{[46-48,55,59]}$ Literatürde, genellikle bildirilen $\% 4,8$ civarında akut böbrek yetmezliğine karşın antibiyotikli çimentoyla yapılan tedavinin başarısızlık oranının \%11'lerde kalması fayda/zarar yönünden bu tedavinin kabul edilebilir olduğunu göstermektedir. ${ }^{[48]}$ Bununla beraber, toksisite bildirilen çalışmaların çoğunda kullanılan vankomisin ( $4 \mathrm{~g}$ ve fazlası) ve özellikle de aminoglikozid ( $1 \mathrm{~g}$ ve fazlası) miktarlarının çok yüksek olması, toksisite gelişmesinde önemli rol oynamış olabilir. ${ }^{[47,48,59-61]}$

Antibiyotikli çimentonun kullanıldığı olgularda doz ayarlamalarının rastgele yapılmaması ve organ fonksiyon bozukluğu olan hastaların durumlarının özenle değerlendirilmesi, oluşabilecek komplikasyonları önlemek açısından büyük önem taşımaktadır.

\section{SONUÇ}

Patojen ve konağa ait birçok biyolojik parametre, osteomiyelit ve artroplasti enfeksiyonunun tedavisi için cerrahi alanda yüksek konsantrasyonda antibiyotik bulunmasına ihtiyaç duyurmaktadır. Geçtiğimiz kırk yıl boyunca bunu sağlamak için kullandığımız antibiyotik yüklü kemik çimentosu; etkin, güvenilir, kolay ulaşıır ve nispeten ucuz bir biyo-materyal olarak karşımıza çıkmaktadır. Antibiyotikli kemik çimentosunun etkinliğini arttıran veya göz ardı edildiği takdirde osteomiyelit tedavisinin başarı şansını azaltacak temel ve pratik bilgiler, her ortopedistin edinmesi gereken bilgilerdir. Antibiyotikli çimento hazırlarken yapılan antibiyotik seçimleri, dozları ve hazırlama tekniklerinin araştıııması ve öğrenilmesi artroplasti ile ilgilenen hekimler açısından büyük önem taşır.

\section{KAYNAKLAR}

1. Bourne RB. Prophylactic use of antibiotic bone cement: an emerging standard -in the affirmative. J Arthroplasty 2004;19(4 Suppl 1):69-72. Crossref

2. Hanssen AD. Prophylactic use of antibiotic bone cement: an emerging standard -in opposition. J Arthroplasty 2004;19(4 Suppl 1):73-7. Crossref

3. Gutowski CJ, Zmistowski BM, Clyde CT, Parvizi J. The economics of using prophylactic antibiotic-loaded bone cement in total knee replacement. Bone Joint J 2014;96$\mathrm{B}(1)$ :65-9. Crossref

4. Srivastav A, Nadkarni B, Srivastav S, Mittal V, Agarwal S. Prophylactic use of antibiotic-loaded bone cement in primary total knee arthroplasty: Justified or not? Indian J Orthop 2009;43(3):259. Crossref

5. Olson ME, Garvin KL, Fey PD, Rupp ME. Adherence of Staphylococcus epidermidis to biomaterials is augmented by PIA. Clin Orthop Relat Res 2006;451:21-4. Crossref

6. Saldarriaga Fernández IC, van der Mei HC, Metzger S, Grainger DW, Engelsman AF, Nejadnik MR, Busscher HJ. In vitro and in vivo comparisons of staphylococcal biofilm formation on a cross-linked poly (ethylene glycol)-based polymer coating. Acta Biomater 2010;6(3):1119-24. Crossref

7. Watnick P, Kolter R. Biofilm, City of Microbes. J Bacteriol 2000;182(10):2675-9. Crossref

8. Scott CP, Higham PA, Dumbleton JH. Effectiveness of bone cement containing tobramycin. An in vitro susceptibility study of 99 organisms found in infected joint arthroplasty. J Bone Joint Surg Br 1999;81-B(3):440-3. Crossref

9. Buchholz HW, Elson RA, Heinert K. Antibiotic-loaded acrylic cement: current concepts. Clin Orthop Relat Res 1984;(190):96-108. Crossref

10. van de Belt $H$, Neut $D$, Schenk W, van Horn JR, van der Mei $\mathrm{HC}$, Busscher HJ. Infection of orthopedic implants and the use of antibiotic-loaded bone cements. A review. Acta Orthop Scand 2001;72(6):557-71. Crossref

11. Jhao $C$, Jiang CC. Two-stage reimplantation without cement spacer for septic total knee replacement. J Formos Med Assoc 2003;102(1):37-41.

12. Kendall RW, Duncan CP, Smith JA, Ngui-Yen JH. Persistence of bacteria on antibiotic loaded acrylic depots. A reason for caution. Clin Orthop Relat Res 1996;329:273-80. Crossref

13. Burnett RSJ, Kelly MA, Hanssen AD, Barrack RL. Technique and timing of two-stage exchange for infection in TKA. Clin Orthop Relat Res 2007;464:164-78. Crossref

14. Leite PS, Figueiredo S, Sousa R. Prosthetic Joint Infection: Report on the One versus Two-stage Exchange EBJIS Survey.J Bone Joint Infect 2016;1:1-6. Crossref

15. Chiu FY, Lin CF, Chen CM, Lo WH, Chaung TY. Cefuroximeimpregnated cement at primary total knee arthroplasty in diabetes mellitus. A prospective, randomised study. J Bone Joint Surg Br 2001;83-B(5):691-5. Crossref 
16. Hansen EN, Adeli B, Kenyon R, Parvizi J. Routine use of antibiotic laden bone cement for primary total knee arthroplasty: impact on infecting microbial patterns and resistance profiles. J Arthroplasty 2014;29(6):1123-7. Crossref

17. Hanssen AD, Spangehl MJ. Practical applications of antibioticloaded bone cement for treatment of infected joint replacements. Clin Orthop Relat Res 2004;427:79-85. Crossref

18. Cui Q. Antibiotic-Impregnated Cement Spacers for the Treatment of Infection Associated with Total Hip or Knee Arthroplasty. J Bone Joint Surg Am 2007;89(4):871. Crossref

19. Duncan CP, Masri BA. The role of antibiotic-loaded cement in the treatment of an infection after a hip replacement. Instr Course Lect 1995;44:305-13.

20. Park SJ, Song EK, Seon JK, Yoon TR, Park GH. Comparison of static and mobile antibiotic-impregnated cement spacers for the treatment of infected total knee arthroplasty. Int Orthop 2010;34(8):1181-6. Crossref

21. Emerson JrRH, Muncie M, TarboxTR, Higgins LL. Comparison of a static with a mobile spacer in total knee infection. Clin Orthop Relat Res 2002;404:132-8. Crossref

22. Greene N, Holtom PD, Warren CA, Ressler RL, Shepherd L, McPherson EJ, Patzakis MJ. In vitro elution of tobramycin and vancomycin polymethylmethacrylate beads and spacers from Simplex and Palacos. Am J Orthop (Belle Mead NJ) 1998;27(3):201-5.

23. Hsieh $\mathrm{PH}$, Tai CL, Lee PC, Chang $\mathrm{YH}$. Liquid gentamicin and vancomycin in bone cement: a potentially more cost-effective regimen. J Arthroplasty 2009;24(1):125-30. Crossref

24. Dunne NJ, Hill J, McAfee P, Kirkpatrick R, Patrick S, Tunney $M$. Incorporation of large amounts of gentamicin sulphate into acrylic bone cement: effect on handling and mechanical properties, antibiotic release, and biofilm formation. Proc Inst Mech Eng H 2008;222(3):355-65. Crossref

25. Penner MJ, Duncan CP, Masri BA. The in vitro elution characteristics of antibiotic-loaded CMW and Palacos- $R$ bone cements. J Arthroplasty 1999;14(2):209-14. Crossref

26. Meyer J, Piller G, Spiegel CA, Hetzel S, Squire M. VacuumMixing Significantly Changes Antibiotic Elution Characteristics of Commercially Available Antibiotic-Impregnated Bone Cements. J Bone Joint Surg Am 2011;93(22):2049-56. Crossref

27. Miola M, Bistolfi A, Valsania MC, Bianco C, Fucale G, Verné E. Antibiotic-loaded acrylic bone cements: An in vitro study on the release mechanism and its efficacy. Mater Sci Eng C 2013;33(5):3025-32. Crossref

28. Grimsrud C, Raven R, Fothergill AW, Kim HT. The In Vitro Elution Characteristics of Antifungal-loaded PMMA Bone Cement and Calcium Sulfate Bone Substitute. Orthopedics 2011;34(8):e378-81. Crossref

29. Adams K, Couch L, Cierny G, Calhoun J, Mader JT. In vitro and in vivo evaluation of antibiotic diffusion from antibioticimpregnated polymethylmethacrylate beads. Clin Orthop Relat Res 1992;(278):244-52. Crossref

30. Nelson CL, Griffin FM, Harrison BH, Cooper RE. In vitro elution characteristics of commercially and noncommercially prepared antibiotic PMMA beads. Clin Orthop Relat Res 1992;(284):303-9. Crossref

31. Joseph TN, Chen AL, Di Cesare PE. Use of antibioticimpregnated cement in total joint arthroplasty. J Am Acad Orthop Surg 2003;11(1):38-47. Crossref

32. Carli A V., Sethuraman AS, Bhimani SJ, Ross FP, Bostrom MPG. Selected Heat-Sensitive Antibiotics Are Not Inactivated During Polymethylmethacrylate Curing and Can Be Used in Cement Spacers for Periprosthetic Joint Infection. J Arthroplasty 2018;33(6):1930-5. Crossref
33. Della Valle AG, Bostrom M, Brause B, Harney C, Salvati EA. Effective bactericidal activity of tobramycin and vancomycin eluted from acrylic bone cement. Acta Orthop Scand 2001;72(3):237-40. Crossref

34. Penner MJ, Masri BA, Duncan CP. Elution characteristics of vancomycin and tobramycin combined in acrylic bonecement. J Arthroplasty 1996;11(8):939-44. Crossref

35. Gallo J, Kolár M, Florschütz A V, Novotný R, Pantucek R, Kesselová M. In vitro testing of gentamicin-vancomycin loaded bone cement to prevent prosthetic joint infection. Biomed Pap 2005;149(1):153-8. Crossref

36. Scott CP, Higham PA. Antibiotic bone cement for the treatment of Pseudomonas aeruginosa in joint arthroplasty: comparison of tobramycin and gentamicin-loaded cements. J Biomed Mater Res B 2003;64B(2):94-8. Crossref

37. Anagnostakos K, Kelm J, Regitz T, Schmitt E, Jung W. In vitro evaluation of antibiotic release from and bacteria growth inhibition by antibiotic-loaded acrylic bone cement spacers. J Biomed Mater Res B 2005;72B(2):373-8. Crossref

38. Bertazzoni Minelli E, Caveiari C, Benini A. Release of antibiotics from polymethylmethacrylate cement. J Chemother 2002;14(5):492-500. Crossref

39. Moojen DJF, Hentenaar B, Charles Vogely $\mathrm{H}$, Verbout AJ, Castelein RM, Dhert WJA. In vitro release of antibiotics from commercial PMMA beads and articulating hip spacers. J Arthroplasty 2008;23(8):1152-6. Crossref

40. Paz E, Sanz-Ruiz P, Abenojar J, Vaquero-Martín J, Forriol F, Del Real JC. Evaluation of Elution and Mechanical Properties of High-Dose Antibiotic-Loaded Bone Cement: Comparative "In Vitro" Study of the Influence of Vancomycin and Cefazolin. J Arthroplasty 2015;30(8):1423-9. Crossref

41. Meani E, Romanò C, Crosby L, Hofmann G, editors. Infection and Local Treatment in Orthopedic Surgery. USA: Springer Science \& Business Media; 2007.

42. Koo KH, Yang JW, Cho SH, Song HR, Park HB, Ha YC, Chang JD, Kim SY, Kim YH. Impregnation of vancomycin, gentamicin, and cefotaxime in a cement spacer for two-stage cementless reconstruction in infected total hip arthroplasty. J Arthroplasty 2001;16(7):882-92. Crossref

43. Kelm J, Regitz T, Schmitt E, Jung W, Anagnostakos K. In vivo and in vitro studies of antibiotic release from and bacterial growth inhibition by antibiotic-impregnated polymethylmethacrylate hip spacers. Antimicrob Agents Chemother 2006;50(1):332-5. Crossref

44. Frew NM, Cannon T, Nichol T, Smith TJ, Stockley I. Comparison of the elution properties of commercially available gentamicin and bone cement containing vancomycin with "home-made" preparations. Bone Joint J 2017;99-B(1):73-7. Crossref

45. Pithankuakul K, Samranvedhya W, Visutipol B, Rojviroj S. The effects of different mixing speeds on the elution and strength of high-dose antibiotic-loaded bone cement created with the hand-mixed technique. J Arthroplasty 2015;30(5):858-63. Crossref

46. Jung J, Schmid NV, Kelm J, Schmitt E, Anagnostakos K. Complications after spacer implantation in the treatment of hip joint infections. Int J Med Sci 2009;6(5):265-73. Crossref

47. Menge TJ, Koethe JR, Jenkins CA, Wright PW, Shinar AA, Miller GG, Holt GE. Acute Kidney Injury After Placement of an Antibiotic-Impregnated Cement Spacer During Revision Total Knee Arthroplasty. J Arthroplasty 2012;27(6):1221-7.e2. Crossref 
48. Luu A, Syed F, Raman G, Bhalla A, Muldoon E, Hadley S, Smith E, Rao M. Two-stage arthroplasty for prosthetic joint infection: a systematic review of acute kidney injury, systemic toxicity and infection control. J Arthroplasty 2013;28(9):1490-8.e1. Crossref

49. Goltzer O, McLaren A, Overstreet D, Galli C, McLemore R. Antimicrobial Release From Prefabricated Spacers Is Variable and the Dose Is Low. Clin Orthop Relat Res 2015;473(7):2253-61. Crossref

50. Martínez-Moreno J, Merino V, Nácher A, Rodrigo JL, Climente M, Merino-Sanjuán M. Antibiotic-loaded Bone Cement as Prophylaxis in Total Joint Replacement. Orthop Surg 2017;9(4):331-41. Crossref

51. Hendriks JGE, van Horn JR, van der Mei HC, Busscher $\mathrm{HJ}$. Backgrounds of antibiotic-loaded bone cement and prosthesis-related infection. Biomaterials 2004;25(3):54556. Crossref

52. Ismael F, Bléton R, Saleh-Mghir A, Dautrey S, Massias L, Crémieux AC. Teicoplanin-containing cement spacers for treatment of experimental Staphylococcus aureus joint prosthesis infection. Antimicrob Agents Chemother 2003;47(10):3365-7. Crossref

53. Chang Y, Chen WC, Hsieh PH, Chen DW, Lee MS, Shih HN, Ueng SWN. In vitro activities of daptomycin-, vancomycin-, and teicoplanin-loaded polymethylmethacrylate against methicillin-susceptible, methicillin-resistant, and vancomycin-intermediate strains of Staphylococcus aureus. Antimicrob Agents Chemother 2011;55(12):5480-4. Crossref

54. Chang YH, Tai CL, Hsu HY, Hsieh PH, Lee MS, Ueng SWN. Liquid antibiotics in bone cement: an effective way to improve the efficiency of antibiotic release in antibiotic loaded bone cement. Bone Joint Res 2014;3(8):246-51. Crossref
55. Hsieh PH, Huang KC, Tai CL. Liquid gentamicin in bone cement spacers: in vivo antibiotic release and systemic safety in two-stage revision of infected hip arthroplasty. J Trauma 2009;66(3):804-8. Crossref

56. Seldes RM, Winiarsky R, Jordan LC, Baldini T, Brause B, Zodda F, Sculco TP. Liquid Gentamicin in Bone Cement. J Bone Joint Surg 2005;87(2):268-72. Crossref

57. Corona PS, Espinal L, Rodríguez-Pardo D, Pigrau C, Larrosa N, Flores X. Antibiotic susceptibility in gram-positive chronic joint arthroplasty infections: increased aminoglycoside resistance rate in patients with prior aminoglycoside-impregnated cement spacer use. J Arthroplasty 2014;29(8):1617-21. Crossref

58. Lutro $O$, Langvatn $H$, Dale $H$, Schrama JC, Hallan $G$, Espehaug B, Sjursen H, Engesæter LB. Increasing Resistance of Coagulase-Negative Staphylococci in Total Hip Arthroplasty Infections:278 THA-Revisions due to Infection Reported to the Norwegian Arthroplasty Register from 1993 to 2007. Adv Orthop 2014;2014:580359. Crossref

59. Roman C, Slama TG. Acute Renal Failure Related to Implanted Antibiotic-Impregnated Cement Joint Spacer. Infect Dis Clin Pr 2015;23(3):e15-6. Crossref

60. Shelly M, Adler T, Slish J. 1295 Acute Kidney Injury Relatd to Antibiotic-Impregnated Orthopedic Cement. Open Forum Infect Dis 2014;1(suppl_1):S50. Crossref

61. Springer BD, Lee GC, Osmon D, Haidukewych GJ, Hanssen $A D$, Jacofsky DJ. Systemic safety of high-dose antibioticloaded cement spacers after resection of an infected total knee arthroplasty. Clin Orthop Relat Res 2004;427:47-51. Crossref 